\title{
Analysis on the Innovation of Rural Tourism Marketing Strategy-Taking the Tik Tok as an Example
}

\author{
Xinxin Shen \\ School of Tourism and Urban-rural Planning, Zhejiang Gongshang University, Hangzhou 310018, \\ China
}

Keywords: Rural tourism, Tik Tok, Marketing innovation

\begin{abstract}
Rural tourism adapts to the unique advantages of the growing demand for short-distance leisure vacations in the urban agglomerations. It shows a vigorous vitality beyond the general tourism industry. How to carry out rural tourism marketing and enhance the popularity of rural tourism has become a top priority. This article takes the Tik Tok as an example to explore why it will become a new way of rural tourism marketing. And think that content, relationship, users are the key factors for the marketing innovation of Tik Tok. Based on this, Propose deepening marketing innovation and promotion strategy: Deepen vertical content and create a brand image; Cultivate fan communities and bring bee colony effects; Promote value creation and reshape marketing vitality.
\end{abstract}

\section{乡村旅游营销策略创新探析一以抖音短视频 APP 为例}

\author{
沈欣欣 \\ 浙江工商大学旅游与城乡规划学院, 浙江 杭州 310018
}

关键词: 乡村旅游 抖音短视频 营销创新

中文摘要.乡村旅游满足城市居民日益增长的周边短途休闲消费需求, 以其独特的优势, 呈现 出乡村旅游业态蓬勃的发展活力。现今如何开展乡村旅游营销, 提升乡村旅游知名度成为研 究的重中之重。本文以抖音短视频为例, 探索抖音短视频何以可能成为乡村旅游营销新利器, 并认为内容、关系、用户是抖音短视频开展营销创新的关键因素。基于此, 提出抖音短视频 深化营销创新提升策略即: 深耕垂直领域, 构筑品牌形象; 培育粉丝社群, 带来蜂群效应; 推动价值共创，重塑营销活力。

\section{1. 引言}

全域旅游发展背景下，乡村旅游能够满足城市居民日益增长的周边短途休闲消费需求， 乡村旅游逐渐成为旅游新风尚, 促进乡村生态优势转化为经济效应与社会效应, 不仅是推动 农村居民实现脱贫攻坚的新举措, 亦是提升城市居民生活质量的重要手段。据相关数据显示, 2018 年全国休闲农业和乡村旅游接待人次超 30 亿, 营业收入超 8000 亿元, 乡村旅游已成为 乡村振兴的引爆点。对于高品质旅游活动的追求, 人们更多的倾向于散客行、自助行, 其获 取信息主要来源于互联网, 乡村旅游依靠传统营销方式已不可行。而抖音作为当代青年中最 具影响力的短视频平台, 极大影响人们的生活方式。近年来伴随着抖音走红的众多景点成为 网红打卡圣地，跟着“抖音打卡”成为旅游新时尚。抖音短视频为旅游目的地营销提供新的平 台, 用户间的内容创造、关系拓展为品牌形象的打造起重要作用。通过对以往研究文献的爬 梳，乡村旅游目的地营销与抖音短视频之间的潜在关联具有普遍性，而且以大数据、互联网 为基础的短视频具有强大的生命力和影响力。正是从这一基本论断出发, 试图分析抖音短视 频在乡村旅游营销中的作用机制，并对已有相关研究进行系统的整合与有益补充。此外，通 
过关注新时代中国乡村旅游问题, 也是基于中国的具体实践对新营销问题的研究进行丰富和 深化，具有深刻的实践意义。

\section{2. “抖音”书写乡村旅游营销何以可能}

乡村旅游传统营销存在渠道系统性不强, 缺乏长期规划的问题。大部分乡村旅游的市场 营销属于短期行为, 缺乏连续性, 因时而动, 因势而发, 只专注于当前活动的宣传, 并未制 定整体性、系统性的宣传策略, 难以给游客留下清晰的认知, 以至于无法留下忠诚游客, 对 乡村带来经济效应与社会效应较为局限。在信息爆炸的今天，如何获得“注意力经济”至关重 要, 现今乡村营销方式单一, 无法满足人们多样化的需求, 且未对旅游项目、旅游产品、农 副产品进行特色包装、策划与推广, 尚未形成自身特色的品牌 IP, 造成产品辐射范围狭小, 知名度与影响力不足等问题。

内容、场景、用户是营销的关键因素，抖音短视频以开放的内容创造，沉浸式的场景体 验, 叠加推送的产品属性, 助力开展形式多元、极具特色的营销传播 ${ }^{1}$ 。依据数据显示, 截至 2018 年 12 月，抖音国内日活跃用户突破 2 亿，国内月活跃用户突破 5 亿，庞大的用户群带 来海量的潜在客户人群。抖音通过对每位用户标签画像, 提取用户兴趣爱好, 以去中心化的 算法推动同质化内容的传播，构建个体现实感，培养用户忠诚度。作为一款音乐社交性质的 短视频 APP，不仅满足了用户深度的参与感，而且激发用户的创造性与主动性，成为年轻人 相互表达观点, 寻找社群认同、展现自我价值的阵地 ${ }^{2}$ 。抖音作为营销领域一个新入口, 将平 台与创意结合起来, 改变了以往的传播方式, 在用户定位上是记录美好生活, 在商业定位上 其重构了人们的表达方式和互动，拉近企业与用户的距离，至今“两微一抖”已成为企业营销 宣传的标配。

\section{3. 抖音短视频: 乡村旅游营销的新利器}

\section{1 构建立体多元的乡村映像}

传统乡村营销所展现的乡村形象多是依靠政府的官方话语传播，传达的是单一的乡村映 像，而以抖音为代表的新媒体是民间话语体系的补充，所传达的不仅仅是乡村形象，更多的 是展现乡村的多维, 每一位用户以自身的感受与情感传达对乡村的某一印象。在镜头下发现 不一样的乡村肌理, 构筑丰富多元的立体形象。热情踊跃的用户们借助抖音平台, 提供了不 同观察视角的短视频, 一个个有趣的短视频将地方的人、事、景连接起来, 呈现真实的生活 状态, 形象逐渐饱满清晰, 处处彰显着人情味与乡土风情, 让乡村细节不断丰富, 进而塑造 出了立体饱满的乡村形象。

\section{2 诠释内涵丰富的乡村意蕴}

抖音用户以创意见长，以异彩纷呈的创造方式展现乡村熟悉的陌生感和陌生的熟悉感。 通过传递乡村生活中被人们忽略的不一样的好奇感, 重塑人们对乡村的认知, 水往高处流的 马鞍山“怪坡”有悖认知常理, 引发全国用户好奇。此外, 通过对孩时记忆中的乡村小吃、儿时 玩要的游戏、玩具等内容展现，激发人们的集体记忆，如茂名特色小吃“箕箕炊”，勾起无数人 怀念家乡的味道。基于共同集体记忆不断产生情感能量, 利用记忆中的情感和符号引发社会 互动, 以丰富社会关系与互动构筑用户自我身份认同与地域文化认同, 唤醒乡愁, 塑造乡村 个性。

\footnotetext{
宋戈,张亦弛.内容、场景与用户有机结合的抖音营销传播[]].传媒,2019(15):50-52.

2 高燕.新媒体时代短视频营销模式的反思和重构——以抖音短视频平台为例[]].出版广角,2019(08):62-64.
} 


\section{4. 以抖音短视频为基础的乡村旅游营销策略提升}

\section{1 深耕垂直领域, 构筑品牌形象}

科特勒认为在人文中心主义 3.0 时代, 营销演变为以独立思想和精神的人为中心，契合 人文、价值、参与、合作、创新等营销新特征的内容营销得以研究 ${ }^{1}$ 。 Harad 认为其与销售无 关, 通过向消费者分享一些强化品牌价值的艺术, 在此过程中催发兴趣, 吸引消费者的目光 与信任 ${ }^{2}$ 。抖音即内容为王, 用户通过 “内容+创意”, 以脑洞大开的形式将一些枯燥乏味的东西 变得有滋有味, 在抖音圈形成自身的社群文化, 激发人们更多的创意想法, 获得更好的表达 与展现。西安永兴坊的摔碗酒、鼓浪屿的土耳其冰淇淋、青海茶卡盐湖等以有趣好玩、极具 创造力、震撼力的优质内容创造吸引众多消费者注意, 迅速走红, 成为打卡圣地, 极大提升 旅游目的地的知名度, 助力旅游品牌形象的构筑。此外, 在提升旅游知名度的同时, 深耕垂 直领域是乡村旅游得以永续发展的必然之路, 售州以“雀州有礼”向全国献礼, 打响“南孔圣地、 睢州有礼”城市品牌，继而推出“衢州有礼一作揖有礼”等一系列创意短视频征集赛，火速刷爆 了抖音、朋友圈, 以一系列子项目不断进行扩充品牌内容, 丰富品牌形象, 展现品牌内涵。

\section{2 培育粉丝社群, 带来蜂群效应}

抖音评论区用户之间的互动至关重要, 超过一半的抖音用户会看评论, 五分之一的用户 会参与评论互动。用户通过相互点赞、转发、评论、模仿建构群体间的认同感与归属感, 构 建“抖友”社群。营销的本质是“构建与顾客一体化的信任关系”，在目的地渠道获取方面发现 $49 \%$ 的女性偏爱朋友圈分享或朋友推荐, 熟人之间的口碑传播成为女性“种草”目的地的主要 渠道。“抖友”社群成员间依据强关系实现信任背书, 抖音大 V 即 KOL (关键意见领袖), 利 用个人信任为产品、品牌做强力支撑, 以强关系推动产品传播。弱关系则具有更强的社会连 结性, 不仅实现信息的广泛快速传播, 而且充当各社群间链接的桥梁, 乡村旅游通过抖音用 户间的弱关系传播, 实现在低成本短时间中与游客建立关系。社群间的强弱关系交错纵横, 社群产生的“蜂群效应”正悄无声息的挑战着传统的营销方式。因此, 在乡村旅游过程中以建 立社群为出发点, 基于相同的兴趣爱好、价值观, 推动社群成员间形成点一点, 点一链, 点 一网彼此互动协作相互交织的网络规模, 促使抖音短视频与乡村旅游产品间、抖音用户间产 生紧密的合作关系以及可持续发展的商业价值。社群力量的传播让营销变得简单直接, 在乡 村旅游营销中注重社群优质内容生产的同时, 亦须塑造乡村旅游传统营销向培育粉丝社群转 变, 从而实现用户沉淀。

\section{3 推动价值共创, 重塑营销活力}

纵观传统的营销传播手段从“独特的消费主张”到在消费者的心智空间寻找一个恰当的定 位，再到“整合营销传播”，其核心在于利用广告媒介传播产品信息 ${ }^{3}$, 而作为产品消费者的价 值则被不同程度的忽略。但在顾客主义时代, 人们的地位与主体性凸显, 顾客不再是产品的 消费者更是价值的创造者。顾客触点丰富多变, 顾客之间的联结比以往任何时候都更加紧密, 社会关系呈网络化发展趋势, 顾客群体具有打造口碑经济的巨大主动权和影响力 ${ }^{4}$ 。每位顾客 都拥有以自己为中心不断延展的社会网络, 信息大量涌动, 顾客作为关系节点, 推动着信息 交换，成为分享资源的主体。抖音短视频平台充分发挥用户间、用户与乡村管理者间的互助 合作, 从单项互动向双向互动转变, 充分挖掘游客价值共创能力, 是实现乡村旅游价值共创 的最佳场域。此外，抖音用户多是以素人草根为主，他们更贴近日常生活，更契合普罗大众 的心理认同, 以不同维度呈现乡村风貌, 增强普通百姓的地方认同感、归属感、获得感与幸

\footnotetext{
1 菲利普·科特勒. 营销革命 3.0: 从产品到顾客, 再到人文精神[M].北京:机械工业出版社,2011:3-25.

2 Harad KC. Content Marketing Strategies to Educate and Entertain[J]. Journal of Financial Planing,2013, 26(3):18-20.

3 国秋华,程夏.移动互联时代品牌传播的场景革命 [J].安徽大学学报(哲学社会科学版),2019,43(01):133-137.

4 卜庆娟,金永生, 李朝辉. 互动一定创造价值吗?一一顾客价值共创互动行为对顾客价值的影响 $[\mathrm{J}]$. 外国经济与管 理,2016,38(09):21-37+50.
} 
福感, 促使广大人民群众积极参与到地方宣传中, 成为乡村旅游建设的主力军。

\section{5. 结语}

社会学家格雷戈里. 贝特森认为内容信息和关系信息是传播内容的两个维度。彭兰指出在 网络传播经历从“内容为王”到“关系为王”的变革 ${ }^{1}$, 而不论是内容或是关系, 两者皆由用户所 产生。内容、关系、用户是抖音短视频推动乡村旅游营销的关键因素, 以优质内容打造品牌, 以强弱关系构筑传播, 以价值共创重塑活力。乡村旅游未来对抖音短视频营销的深入挖掘与 有益探索, 需要在市场层面有机实现内容创造、关系传播与用户共创价值的深度融合, 推动 乡村旅游品牌在愈演愈烈的市场竞争中脱颖而出。总体而言, 乡村旅游营销中依靠某一手段 无法满足市场需求, 须将自媒体、短视频与传统营销有效结合, 多渠道、多方位进行宣传。 做足宣传“外功”, 苦练服务“内功”, 内外结合推动乡村旅游蓬勃振兴。然而本文在研究中存在 不足, 笔者仅以抖音短视频 APP 为例, 探索在乡村旅游营销中的应用, 缺乏一定的全面性, 希望在以后的研究中能够进一步整体性、系统性的深入探索。

\section{References}

[1] Song Ge, Zhang Yichi. Tik Tok marketing communication with content, scene and user. Media, vol.15, pp. 50-52,2019.

[2] Philip Kotler. Marketing 3.0: From Products to Customers to the Human Spirit. BeiJing: China Machine Press, pp.3-25,2011.

[3] Harad KC. Content Marketing Strategies to Educate and Entertain. Journal of Financial Planning, vol.26, pp.18-20,2013.

[4] Guo Qiuhua, Cheng Xia. Scene Revolution of Brand Communication in Mobile Internet Era. Journal of Anhui University (Philosophy and Social Sciences Edition), vol. 43, pp.133-137,2019.

[5] Bu QingJuan, Jin Yongshen, Li Zhaohui. Does Interactive Behavior Certainly Create Value? The Effect of Customer Value Co-creation Interactive Behavior on Customer Value. Foreign Economics \& Management, vol.38, pp.21-37+50, 2016.

1 彭兰.从“大众门户”到“个人门户”一网络传播模式的关键变革 [J].国际新闻界,2012,34（10）:6-14. 